Triebner 2016

\title{
Menopause is associated with accelerated lung function decline
}

Kai Triebner ${ }^{1,2}$, Bobette Matulonga ${ }^{3}$, Ane Johannessen ${ }^{1,4}$, Sandra Suske ${ }^{2}$, Bryndís

Benediktsdóttir $^{5}$, Pascal Demoly ${ }^{6}$, Shyamali C Dharmage ${ }^{7}$, Karl A Franklin ${ }^{8}$, Judith Garcia Aymerich $^{9,10,11}$, José Antonio Gullón Blanco ${ }^{12}$, Joachim Heinrich ${ }^{13}$, Mathias Holm ${ }^{14}$, Debbie Jarvis $^{15}$, Rain Jõgi ${ }^{16}$, Eva Lindberg ${ }^{17}$, Jesús Martínez Moratalla Rovira ${ }^{18}$, Nerea Muniozguren Agirre $^{19}$, Isabelle Pin ${ }^{20}$, Nicole Probst-Hensch ${ }^{21,}{ }^{22}$, Luca Puggini ${ }^{23}$, Chantal Raherison ${ }^{24}$, José Luis Sánchez-Ramos $^{25}$, Vivi Schlünssen ${ }^{26,27}$, Jordi Sunyer ${ }^{9,10,11,28}$, Cecilie Svanes ${ }^{29,30}$, Steinar Hustad ${ }^{1,2}$, Bénédicte Leynaert*31 and Francisco Gómez Real*1,32

*Shared last authorship

${ }^{1}$ Department of Clinical Science, University of Bergen, Bergen, Norway, ${ }^{2}$ Core Facility for Metabolomics, University of Bergen, Bergen, Norway, ${ }^{3}$ Pathophysiology and Epidemiology of Respiratory Diseases, Inserm UMR1152, Paris, France, ${ }^{4}$ Department of Global Public Health and Primary Care, University of Bergen, Bergen, Norway, ${ }^{5}$ Faculty of Medicine, University of Iceland, Reykjavik, Iceland, ${ }^{6}$ Department of Pulmonology - Division of Allergy, University Hospital of Montpellier, Montpellier, France, ${ }^{7}$ Allergy and Lung Health Unit, Melbourne School of Population Health, University of Melbourne, Melbourne, Australia, ${ }^{8}$ Department of Surgical and Perioperative Sciences, Umeå University, Umeå, Sweden, ${ }^{9}$ ISGlobal, Centre for Research in Environmental Epidemiology, Barcelona Biomedical Research Park, Barcelona, Spain, ${ }^{10}$ Universitat Pompeu Fabra, Barcelona, Spain, ${ }^{11}$ CIBER Epidemiología y Salud Pública, Barcelona, Spain, ${ }^{12}$ Departement of Pneumology, Hospital San Agustin de Aviles, Oviedo, Spain, ${ }^{13}$ Institute and Outpatient Clinic for Occupational, Social and Environmental Medicine, Ludwig Maximilians University Munich, 
Triebner 2016

Munich, Germany, ${ }^{14}$ Department of Occupational and Environmental Medicine, University of Gothenburg, Göteborg, Sweden, ${ }^{15}$ Department of Respiratory Epidemiology, Occupational Medicine and Public Health, Imperial College, London, United Kingdom, ${ }^{16}$ Department of Lung Medicine, Tartu University Clinic, Tartu, Estonia, ${ }^{17}$ Department of Medical Sciences, Lungmedicine and Allergology, Uppsala University, Uppsala, Sweden, ${ }^{18}$ Servicio de Neumología, Servicio de Salud de Castilla - La Mancha, Albacete, Spain, ${ }^{19}$ Epidemiologia, Salud Pública, Dep. Salud, Gobierno Vasco, Hospital, Galdakao, Spain, ${ }^{20}$ Pneumologie Pédiatrique, Antenne Pédiatrique du CIC, Centre Hospitalier Universitaire Grenoble Alpes, Grenoble, France, ${ }^{21}$ Swiss Tropical and Public Health Institute, Basel, Switzerland, ${ }^{22}$ Department of Public Health, University of Basel, Basel, Switzerland, ${ }^{23}$ Department of Electronic Engineering, University of Ireland, Maynooth, Ireland, ${ }^{24}$ U1219, Bordeaux Population Health Research Center, Bordeaux, France, ${ }^{25}$ Department of Nursing, University of Huelva, Huelva, Spain, ${ }^{26}$ Department of Public Health, Aarhus University, Aarhus, Denmark, ${ }^{27}$ National Research Center for the Working Environment, Copenhagen, Denmark, ${ }^{28}$ Hospital del Mar Medical Research Institute, Barcelona, Spain, ${ }^{29}$ Department of Occupational Medicine, Haukeland University Hospital, Bergen, Norway, ${ }^{30}$ Centre for International Health, University of Bergen, Bergen, Norway, ${ }^{31}$ Team of Epidemiology, Inserm UMR1152, Paris, France, ${ }^{32}$ Department of Gynecology and Obstetrics, University of Bergen, Bergen, Norway; 
Triebner 2016

\section{Corresponding author}

Kai Triebner, MSc.

Department of Clinical Science

University of Bergen

Jonas Lies veg 87

5021 Bergen

Norway

Telephone: +4745031557

E-mail: kai.triebner@uib.no

\section{Contributorship}

Kai Triebner:

Principal author, conception and design of the work, acquisition, analysis, and interpretation of data, drafting the work and revising for important intellectual content;

Bobette Matulonga, Ane Johannessen:

Interpretation of data and revising for important intellectual content;

Sandra Suske, Steinar Hustad:

Acquisition, analysis, and interpretation of data and revising for important intellectual content;

Luca Puggini:

Analysis and interpretation of data and revising for important intellectual content; 
Triebner 2016

Bryndís Benediktsdóttir, Pascal Demoly, Shyamali C Dharmage, Karl A Franklin, Judith Garcia Aymerich, José Antonio Gullón Blanco, Joachim Heinrich, Mathias Holm, Debbie Jarvis, Rain Jõgi, Eva Lindberg, Jesús Martínez Moratalla Rovira, Nerea Muniozguren Agirre, Isabelle Pin, Nicole Probst-Hensch, Chantal Raherison, José Luis Sánchez-Ramos, Vivi Schlünssen, Jordi Sunyer, Cecilie Svanes:

Conception and design of the work, acquisition and interpretation of data and revising for important intellectual content;

Bénédicte Leynaert, Francisco Gómez Real:

Conception and design of the work, acquisition, analysis, and interpretation of data, drafting the work and revising for important intellectual content;

\section{Declaration of financial support}

Kai Triebner has received a $\mathrm{PhD}$ scholarship from the Norwegian Research Council (Application Number: ES515063 Project Number: 228174). The European Commission supported ECRHS, as part of the "Quality of Life" program. Bodies funding the local studies in ECRHS are listed in the online data supplement.

\section{Running head}

Menopause accelerates lung function decline

\section{Descriptor number}

2.03 Health Education/Disease Prevention/Patient Education 
Triebner 2016

Word count 2898

\section{At a Glance Commentary}

The present study is the first to investigate the effect of menopause on lung function in a large, longitudinal and population-based survey. We analyzed the decline of forced vital capacity and forced expiratory volume in one second as related to menopausal status. The study population is a hormonally well-defined group of women, aggregated by latent class analysis on measurements of follicle stimulating hormone and luteinizing hormone as well as questionnaire data. Linear mixed effects models showed that postmenopausal women and women in the menopausal transition are associated with a steeper decline in lung function, beyond the age related decline, compared to nonmenopausal women. Our findings are relevant for clinical practice and health care professionals should be aware that women undergoing the menopausal transition are at risk of accelerated lung function decline.

\section{Online data supplement}

This article has an online data supplement, which is accessible from this issue's table of content online at www.atsjournals.org 
Triebner et al

\begin{abstract}
Rationale: Menopause is associated with changes in sex hormones, which affect immunity, inflammation, and osteoporosis and may impair lung function. Lung function decline has not previously been investigated in relation to menopause.
\end{abstract}

Objectives: To study whether lung function decline, assessed by forced vital capacity and forced expiratory volume in one second, is accelerated in women who undergo menopause.

Methods: The population-based longitudinal European Community Respiratory Health Survey provided serum samples, spirometry and questionnaire data about respiratory and reproductive health from three study waves $(\mathrm{N}=1438)$. We measured follicle stimulating hormone and luteinizing hormone and added information on menstrual patterns, to determine menopausal status using latent class analysis. Associations with lung function decline were investigated using linear mixed effects models, adjusting for age, height, weight, packyears, current smoking, age at completed full-time education, spirometer and including study center as random effect.

Measurements and Main Results: Menopausal status was associated with accelerated lung function decline. The adjusted mean forced vital capacity decline was increased by -10.2 $\mathrm{ml} / \mathrm{yr}(95 \%$ Confidence interval -13.1 to -7.2$)$ in transitional women and $-12.5 \mathrm{ml} / \mathrm{yr}(-16.2$ to -8.9) in postmenopausal women, compared to women menstruating regularly. The adjusted mean forced expiratory volume in one second decline increased by $-3.8 \mathrm{ml} / \mathrm{yr}(-6.3$ to -2.9$)$ in transitional women and $-5.2 \mathrm{ml} / \mathrm{yr}(-8.3$ to -2.0$)$ in postmenopausal women. 
Conclusions: Lung function declined more rapidly among transitional and postmenopausal women, in particular for forced vital capacity, beyond the expected age change. Clinicians should be aware that respiratory health often deteriorates during reproductive aging.

\section{Key words}

Latent class analysis; lung function decline; menopause; reproductive aging; sex hormones;

\section{Word count abstract}

\section{Abbreviations used}

BLUP: Best Linear Unbiased Prediction

BMI: Body Mass Index

CI: Confidence Interval

$\mathrm{FEV}_{1}$ : Forced Expiratory Volume In One Second

FSH: Follicle Stimulating Hormone

FVC: Forced Vital Capacity

LH: Luteinizing Hormone

OBS: Observations

SD: Standard Deviation 


\section{INTRODUCTION}

The non-reproductive phase of a woman's life begins with menopause (1). Cessation of menstruations may be accompanied by lack of energy, hot flushes, vaginal discharge, insomnia, osteoporosis and an increased risk of developing chronic conditions like diabetes and cardiovascular disease (2-6). Menopause is associated with profound changes in the activity of the hypothalamo-pituitary-gonadal axis: as $17 \beta$-estradiol production in the ovaries ceases, follicle stimulating hormone (FSH) and luteinizing hormone (LH) concentrations rise $(7,8)$. Low levels of $17 \beta$-estradiol are associated with increased systemic inflammation and inflammation in the lungs (9-16). The inflammation markers C-reactive protein and Interleukin-6 are inversely associated with forced vital capacity (FVC) and forced expiratory volume in one second $\left(\mathrm{FEV}_{1}\right)(17,18)$. These findings point towards a possible association between menopause and increased lung function decline. Given today's life expectancy far beyond the age of menopause, understanding how to maintain good health and quality of life in later years is important $(1,19-22)$. The role of sex hormones in respiratory health is increasingly acknowledged (23-32). However, potential changes in respiratory health as related to reproductive aging in women are still poorly understood $(23,33,34)$. A recent longitudinal analysis of a large population based survey showed higher incidence of newonset asthma and increase in respiratory symptoms as related to menopause (28). Potential changes in lung function with menopause have only been addressed in cross-sectional analyses: One population-based study of women aged 45 to 55 years, not using hormone replacement therapy, found lower lung function in postmenopausal women compared to women who still had regular menstruations (27). A recent study from the UK Biobank found an association between cessation of menstruation and lower lung function, whereas another study saw no independent effect of menopause on $\mathrm{FVC}$ and $\mathrm{FEV}_{1}$ levels $(35,36)$. It has been reported that lifestyle factors such as smoking may be more detrimental after menopause, 
while some hormone replacement therapy regimens appear to be associated with higher lung function in postmenopausal women (37-39). Whether obesity impacts on respiratory health in menopause is not known, although sex hormones and body fat mass are interrelated $(40,41)$ and effect modification of BMI on the role of hormone replacement therapy is suggested in cross-sectional studies (42). The aim of the present study was to investigate the association of menopausal status with decline in lung function over a 20 -year period, using data from a large European, population-based cohort. Some of the results of this study have been previously reported in the form of an abstract to the European Respiratory Society annual congress (43). 


\section{METHODS}

\section{Study population}

The European Respiratory Health Survey (ECRHS) is an international multicenter study including three waves, ECRHS 1 in 1991-1994, ECRHS 2 in 1998-2002 and ECRHS 3 in 2010-2012, and is described in detail at http://www.ecrhs.org. The age range at baseline was 25 to 48 years and the median observation time for women participating in all three waves was $19.7(17.9$ - 22.4) years. The present study includes 19 centers in Europe (see Table E1 in the online data supplement). The examinations included an interviewer-led questionnaire, spirometry and serum sampling. At ECRHS 2 and 3 women additionally answered standardized questionnaires on women's health. For 2484 women, serum samples from ECRHS 2 and/or 3 were analyzed for FSH and LH (see online data supplement). Inclusion criteria are presented in Figure 1. Ethical approval was obtained from the appropriate ethics committee and each participant provided informed written consent.

Figure 1. Study population with inclusion criteria (*height and packyears)

\section{Classification according to menopausal status}

Every woman contributed with up to three observations (ECRHS 1, 2 and/or 3, $\mathrm{N}_{\mathrm{obs}}=3295$ ). We attributed each observation separately to a menopausal status, at the same time as the pulmonary function tests were conducted. At baseline we included only nonmenopausal women, excluding women who retrospectively reported their last period more than one year before baseline. To determine menopausal status at ECRHS 2 and 3 we performed latent class analysis in order to identify subgroups within our population, based on menopause related factors such as hormone levels and presence and/or regularity of menstruations (44, 45). Latent class analysis is commonly used in medical research to classify subjects by selected characteristics ( $>2000$ publications listed on www.PubMed.gov). The number of 
classes was restricted to three, retrospectively labeled: nonmenopausal, transitional and postmenopausal. Observations were assigned class-memberships based on response probabilities (see Table E2 in the online data supplement). The algorithm, grouping the most similar observations, was repeated 30 times with a maximum of 10.000 iterations. The included categorical variables were FSH in quintiles, $\mathrm{LH}$ in quintiles and menstrual status as reported by participants (see Table E2 in the online data supplement). Each participant was present either in one, two or all three classes, representing the reproductive stage at different waves.

\section{Outcomes}

FVC and $\mathrm{FEV}_{1}$ were recorded following standardized methods $(46,47)$. The spirometers that were used are presented in Table E1 in the online data supplement.

\section{Statistical analysis}

Data of all three waves was modeled by linear mixed effects models, allowing for random intercepts (48). By including spirometric measurements and an interaction term of the menopausal status with age, we determined the lung function decline defined as the slope of change in lung capacity, which can be interpreted as the mean annual decline $[\mathrm{ml} / \mathrm{yr}]$ associated with each menopausal status. We adjusted for fixed effects of age, weight, packyears, current smoking and type of spirometer at each wave, as well as height at baseline and age at completed full time education as a socioeconomic proxy, which if missing $(6.0 \%)$ was imputed as the population mean. Missing age (3.8\%) and weight $(9.4 \%)$ were included as age and weight at a different wave plus the mean increase during follow-up. The participant's id number, nested in the respective study center, was accounted for as random effect. Stratified analyses were performed among never-smokers, ever-smokers and BMI categories 
according to the World Health Organization. To investigate whether results were driven by a history of asthma, or gynecological disorders such as polycystic ovary syndrome, endometriosis, surgical menopause (reported at ECRHS 2 or 3$)$ or premature menopause $(<40$ years), we performed sensitivity analysis within the respective subgroups without these conditions. We further tested potential heterogeneity between study centers and an alternative model, accounting for change in height over the study period. Analyses were performed using R (Version 3.1.0, The R Foundation for Statistical Computing). 


\section{RESULTS}

Characteristics of the subjects at baseline are presented in Table 1. The class conditional probabilities and standard errors for the class membership, determined by latent class analysis, can be found in Table E2 in the online data supplement.

Table 1. Characteristics of the study population at baseline $\left(n=1369^{1}\right)$

\begin{tabular}{|c|c|}
\hline & Median $\left(5^{\text {th }}, 95^{\text {th }}\right.$ percentile $)$ \\
\hline Age [yr] & $36.2(26.8,45.0)$ \\
\hline Height [m] & $1.64(1.52,1.75)$ \\
\hline Weight $[\mathrm{kg}]$ & $61(50,85)$ \\
\hline BMI $\left[\mathrm{kg} / \mathrm{m}^{2}\right]$ & $22.6(18.8,31.2)$ \\
\hline Packyears & $1.0(0.0,24.0)$ \\
\hline Current smoking, n (\%) & $438(32)$ \\
\hline Year of PFT ${ }^{1}$ & $1992(1991,1993)$ \\
\hline Observation time [yr] & $19.7(18.5,21.0)$ \\
\hline FVC [L] & $3.85(2.94,4.80)$ \\
\hline $\operatorname{FEV}_{1}[\mathbf{L}]$ & $3.19(2.37,3.96)$ \\
\hline Delta FVC ${ }^{2}[\mathrm{ml} / \mathrm{yr}]$ & $25.8(2.4,53.6)$ \\
\hline Delta FEV ${ }_{1}^{2}[\mathrm{ml} / \mathrm{yr}]$ & $33.4(10.7,56.9)$ \\
\hline
\end{tabular}

The included 1438 women provided a total of 3295 complete observations (pulmonary function tests) including data on menopausal status and covariates (up to three observations per woman). The nonmenopausal class included $60 \%\left(\mathrm{n}_{\mathrm{obs}}=1992\right)$, the transitional class $18 \%$ $\left(\mathrm{n}_{\mathrm{obs}}=583\right)$ and the postmenopausal class $22 \%\left(\mathrm{n}_{\mathrm{obs}}=720\right)$ of the observations. The mean age was 39 years in the nonmenopausal, 53 years in the transitional and 56 years in the postmenopausal class (Table 2). Weight and BMI were highest in the transitional class (Table 2). 
Table 2. Characteristics of the observations by menopausal class, mean (SD)

\begin{tabular}{lccc} 
& $\begin{array}{c}\text { Nonmenopausal } \\
\left(\mathrm{n}_{\text {obs }}=\mathbf{1 9 9 2}\right)\end{array}$ & $\begin{array}{c}\text { Transitional } \\
\left(\mathrm{n}_{\text {obs }}=\mathbf{5 8 3}\right)\end{array}$ & $\begin{array}{c}\text { Postmenopausal } \\
\left(\mathrm{n}_{\text {obs }}=\mathbf{7 2 0}\right)\end{array}$ \\
\hline Age $[\mathbf{y r}]$ & $38.8(6.8)$ & $52.8(8.2)$ & $55.7(5.4)$ \\
Height [m] & $1.64(0.07)$ & $1.63(0.07)$ & $1.63(0.07)$ \\
Weight $[\mathbf{k g}]$ & $65.2(12.6)$ & $71.7(15.2)$ & $69.3(12.5)$ \\
BMI [kg/m $\left.{ }^{2}\right]$ & $24.2(4.5)$ & $26.8(5.4)$ & $26.0(4.4)$ \\
\hline Packyears & $6.2(10.3)$ & $9.2(16.5)$ & $9.5(17.9)$ \\
Current smoking, $\mathbf{n}(\%)$ & $581(29)$ & $120(21)$ & $115(16)$ \\
\hline FVC [L] & $3.81(0.58)$ & $3.41(0.60)$ & $3.35(0.54)$ \\
FEV $\mathbf{1}[\mathbf{L}]$ & $3.11(0.50)$ & $2.64(0.53)$ & $2.55(0.45)$ \\
\hline FSH [IU/L] & $9.3(9.9)$ & $56.8(40.9)$ & $146.9(80.0)$ \\
LH [IU/L] & $5.8(5.7)$ & $20.1(10.0)$ & $35.5(11.0)$ \\
\hline
\end{tabular}

Figures 2 and 3 show the best linear unbiased predictions (BLUP's) for FVC and FEV 1 of the whole population, obtained by adding together the population predictions (based on the fixed effects estimates) and the estimated contributions of the random effects (48). Both curves show a negative increase in slope when a large proportion of women enter the transitional or menopausal stage.

Figure 2. Best linear unbiased predictions for FVC of the study population ( $\mathrm{n}=1438)$ according to the specified linear mixed effects model, including $95 \% \mathrm{CI}$ and population distribution by menopausal class (The dotted line, as visual aid continues the initial slope).

Figure 3. Best linear unbiased predictions for $\mathrm{FEV}_{1}$ of the study population $(\mathrm{n}=1438)$ according to the specified linear mixed effects model, including $95 \%$ CI and population distribution by menopausal class (The dotted line, as visual aid continues the initial slope).

The mean age dependent lung function decline for all groups was $-15.9 \mathrm{ml} / \mathrm{yr}(95 \% \mathrm{CI}-18.2$ to -13.6$)$ for $\mathrm{FVC}$ and $-24.0 \mathrm{ml} / \mathrm{yr}(-25.9$ to -22.0$)$ for $\mathrm{FEV}_{1}$. The interaction term of menopausal status with age showed that the mean FVC decline was additionally increased by $-10.2 \mathrm{ml} / \mathrm{yr}(-13.1$ to -7.2$)$ for women classified as transitional and $-12.5 \mathrm{ml} / \mathrm{yr}(-16.2$ to -8.9$)$ for women classified as postmenopausal, compared to women menstruating regularly. The mean $\mathrm{FEV}_{1}$ decline additionally increased by $-3.8 \mathrm{ml} / \mathrm{yr}(-6.3$ to -2.9$)$ for women classified as transitional and by $-5.2 \mathrm{ml} / \mathrm{yr}(-8.3$ to -2.0$)$ for women classified as postmenopausal. 
Current smoking was significantly associated with $\mathrm{FEV}_{1}$ decline [-29.3 $\mathrm{ml}$ (-54.0 to -4.7)] compared to former smoking and lifelong non-smoking, whereas packyears were significantly associated with both $\mathrm{FEV}_{1}$ decline $[-2.3 \mathrm{ml} /$ packyear $(-3.0$ to -1.5$)]$ and $\mathrm{FVC}$ decline $[-1.0 \mathrm{ml} /$ packyear $(-1.9$ to -0.1$)]$. The results for other covariates of the primary analysis are presented in Tables E3 and E4 in the online data supplement.

Analysis of FVC decline as related to menopause and stratified according to BMI at ECRHS 3 showed a higher age related decline (Figure 4) and indicated a smaller menopause related decline with increasing BMI ( $\mathrm{p}_{\text {interaction }}<0.01$ for transitional women and $\mathrm{p}_{\text {interaction }}<0.001$ for postmenopausal women) (Figure 5). Ever smokers indicated a higher age related decline and higher menopause related decline than never smokers. For $\mathrm{FEV}_{1}$ we observed a similar but less distinct pattern (Figure 4 and Figure 5).

Figure 4. Age related lung function decline by smoking and BMI for the study population, $\mathrm{ml} / \mathrm{yr}$ Figure 5. Menopause related lung function decline by smoking and BMI for the menopausal class, $\mathrm{ml} / \mathrm{yr}$

The sensitivity analysis showed that the results were not driven by a history of asthma, by gynecological disorders, by hypertension or cardiovascular disorders, or by surgical or premature menopause (data not given). Results were consistent for individual centers with sufficient participants (Galdakao, Albacete, Grenoble, Paris, Reykjavik, Bergen, Umeå and Uppsala).

Height changed over the study period. The age related decline in height was $-0.23 \mathrm{~mm} / \mathrm{yr}$ (95\% CI -0.38 to -0.08$)$. Women in the menopausal transition had an additional decline of $0.62 \mathrm{~mm} / \mathrm{yr}(-0.79$ to -0.05$)$ and the postmenopausal class an additional decline of -0.77 $\mathrm{mm} / \mathrm{yr}$ (-0.98 to -0.06$)$. The alternative model accounting for change in height showed a $25 \%$ reduced, yet still significant, decline in FVC for both the transitional [-7.7 $\mathrm{ml} / \mathrm{yr}(-10.6$ to 4.7)] and the postmenopausal class $[-9.0 \mathrm{ml} / \mathrm{yr}(-12.7$ to -5.5$)]$, compared to the 
nonmenopausal class. The decline for $\mathrm{FEV}_{1}$ was reduced by circa $50 \%$ and not significant after such adjustment (transitional class: $-2.1 \mathrm{ml} / \mathrm{yr}(-4.7$ to 0.3$)$, postmenopausal class: -2.6 $\mathrm{ml} / \mathrm{yr}(-5.8$ to 0.5$)$ 


\section{DISCUSSION}

This population-based study of 1438 women aged 25-48 years from nine European countries over 20 years with repeated spirometry, hormone measurements and questionnaire data, found that lung function declined more rapidly in women who were transitional or postmenopausal, as compared to women who were nonmenopausal. To our knowledge, this is the first longitudinal population-based study that investigates lung function decline in relation to menopause.

The menopause related decline was more pronounced for FVC than for $\mathrm{FEV}_{1}$, which points towards a restrictive rather than an obstructive pattern. Stratified analyses and sensitivity analyses revealed that these findings were very robust. Effect modification by BMI seems plausible, as circulating androgens are converted to estrogens in adipose tissue. Ever smokers show a suggested steeper decline in both age and menopause related impairment of lung function, possibly because of a combined effect of smoking on the lungs and its antiestrogenic effects. Sensitivity analyses in women without a history of asthma, surgical menopause or gynecological disorders, showed similar and statistically significant results.

We used latent class analysis to define the menopausal status rather than fixed cut-offs, as this type of analysis accounts better for the underlying biology and the information gathered from the participants. Clustering of the most similar observations forms the latent classes, and the multivariate and repetitive nature of the classification process allows for a dynamic grouping based on maximum likelihood criteria. We restricted classification to three classes as the data favored more classes by a marginally better fit, yet it supported a structure of two clearly defined classes (nonmenopausal and postmenopausal), as well as a more heterogeneous class representing different stages within the menopausal transition. The transitional class might include a minority of postmenopausal and nonmenopausal women. 
Hormone levels of women above 60 years who were still categorized as transitional are on average lower than in women categorized as postmenopausal. The trajectories of FSH over the menopausal transition are not uniform across the population; e.g. women with a higher BMI or expressed sexuality are more likely to show a slower increase and lower postmenopausal level of FSH (49-51). These women are most likely postmenopausal, however hormonally they are more similar to the transitional class, as determined by the latent class analysis $(7,8)$. The heterogeneity of the transitional class might dilute associations slightly.

Hormonal changes in menopause, linked to complex biological events might contribute to the demonstrated acceleration in lung function decline with menopause. One possible mechanism is systemic inflammation, which is associated with menopausal hypoestrogenism and impaired lung function. The way $17 \beta$-estradiol affects inflammation depends strongly on the type of inflammatory or immunogenic stimulus, the involved cell types, the target organ's specific microenvironment and metabolism, leading to different anti- and proinflammatory effects $(10,52)$. Animal models suggest that low levels of $17 \beta$-estradiol might amplify inflammation and higher levels might attenuate it $(11,12)$. In rats and mice, surgically induced menopause enhances pleural exudation, leukocyte migration and lung myeloperoxidase activity amongst others $(13,14)$. Ovariectomy is further associated with increased levels of inflammatory markers, which decreased after $17 \beta$-estradiol substitution $(13,14)$. A comprehensive review concluded that in all available inflammatory models of the lung, 17ß-estradiol was demonstrated to have an anti-inflammatory effect (10).

Further, hypoestrogenism plays a critical role in osteoporosis, which results in reduced height of the thoracic vertebrae which may mechanically reduce the expansion of the thoracic cage during inspiration and place the diaphragm in a suboptimal position $(53,54)$. Our findings 
suggested that the accelerated decline related to menopause was in part explained by osteoporosis, as accounting for change in height attenuated the associations of menopause with decline in FVC as well as $\mathrm{FEV}_{1}$.

Strengths of the present study are the availability of repeatedly measured lung function and hormone measurements as well as interview/questionnaire data for large population samples. A unique window of opportunity was taken advantage of, as the study subjects were aged 2548 years at baseline and most women went through the age of the menopausal transition during the 20-year follow-up. Hormone measurements at two time points are a major strength of this analysis, as well as the use of latent class analyses to define menopause based on both hormone measurement and questionnaire information. The crude definition of menopause at baseline, only based on questionnaire data, is a weakness of the study that may have introduced minor non-differential error and thus attenuated true results. The outcomes of the study, objectively measured lung function parameters are a strength and spirometric measurement error is unlikely to be related to menopausal status. The change in spirometers between surveys is accounted for in the analyses, however, it is possible that a residual nondifferential measurements error may have attenuated the true results. The multinational and multi-centric design of the study allows for high external validity and the consistency across geographic and cultural borders suggests biologic explanatory mechanism rather than confounding by sociocultural factors.

\section{Conclusions}

The present study shows that menopause was associated with an accelerated decline in lung function, beyond the expected age related decline. This was most pronounced for FVC. The results were consistent across subgroups and independent of smoking history. The effect size for $\mathrm{FEV}_{1}$ was comparable to smoking 20 cigarettes per day for two years, and for FVC to 
smoking 20 cigarettes per day for ten years. The mechanisms underlying the associations between reproductive aging and respiratory health need to be further investigated. Future studies should address potential beneficial effects of hormone replacement therapy. The results from the present study should be taken into account, as they are highly relevant for the health and quality of life of a large and steadily increasing number of women.

\section{ACKNOWLEDGMENTS}

We thank all participants, field workers and coordinators of the ECRHS 1, 2 and 3 for their efforts as well as Ersilia Bifulco from the Core Facility for Metabolomics at the University of Bergen and Guy Goertz and Fathi Driss, from the Hôpital Xavier Bichat in Paris for work done in connection with the hormone measurements. Further we are very grateful for the travel support, granted by EPINOR. 


\section{References}

1. WHO Scientific Group on Research on the Menopause in the 1990s (1994 : Geneva SWHO. Research on the menopause in the 1990s : report of a WHO scientific group Geneva: WHO; 1996.

2. Dennerstein L, Dudley EC, Hopper JL, Guthrie JR, Burger HG. A prospective populationbased study of menopausal symptoms. Obstetrics and gynecology 2000; 96: 351-358.

3. Martinez Perez JA, Palacios S, Garcia FC, Perez M. Assessing osteoporosis risk factors in Spanish menopausal women. Gynecological endocrinology : the official journal of the International Society of Gynecological Endocrinology 2011; 27: 807-813.

4. Carr MC. The emergence of the metabolic syndrome with menopause. The Journal of clinical endocrinology and metabolism 2003; 88: 2404-2411.

5. Ventetuolo CE, Ouyang P, Bluemke DA, Tandri H, Barr RG, Bagiella E, Cappola AR, Bristow MR, Johnson C, Kronmal RA, Kizer JR, Lima JA, Kawut SM. Sex hormones are associated with right ventricular structure and function: The MESA-right ventricle study. American journal of respiratory and critical care medicine 2011; 183: 659667.

6. Young T, Finn L, Austin D, Peterson A. Menopausal status and sleep-disordered breathing in the Wisconsin Sleep Cohort Study. American journal of respiratory and critical care medicine 2003; 167: 1181-1185.

7. Speroff L, Glass RH, Kase NG. Menopause and the Perimenopausal transition. In: Mitchell C, editor. Clinical Gynecologic Endocrinology and Infertility, 6th ed. Baltimore: Lippincott Williams\&Wilkins; 1999. p. 643-724.

8. Speroff L, Glass RH, Kase NG. Clinical gynecologic endocrinology and infertility. In: Mitchell C, editor. Clinical gynecologic endocrinology and infertility, 6th ed. Baltimore: Lippincott Williams \& Wilkins; 1999.

9. Zhao J, Jiang CQ, Lam TH, Liu B, Cheng KK, Kavikondala S, Zhang WS, Leung GM, Schooling CM. Genetically predicted 17 beta-estradiol and systemic inflammation in women: a separate-sample Mendelian randomisation analysis in the Guangzhou Biobank Cohort Study. Journal of epidemiology and community health 2014; 68: 780785.

10. Straub RH. The Complex Role of Estrogens in Inflammation. Endocrine reviews 2007; 28: 521-574.

11. Cuzzocrea S, Mazzon E, Sautebin L, Serraino I, Dugo L, Calabró G, Caputi AP, Maggi A. The protective role of endogenous estrogens in carrageenan-induced lung injury in the rat. Molecular Medicine 2001; 7: 478-487.

12. Esposito E, Iacono A, Raso GM, Pacilio M, Coppola A, Di Carlo R, Meli R. Raloxifene, a selective estrogen receptor modulator, reduces carrageenan-induced acute inflammation in normal and ovariectomized rats. Endocrinology 2005; 146: 33013308.

13. Speyer CL, Rancilio NJ, McClintock SD, Crawford JD, Gao H, Sarma JV, Ward PA. Regulatory effects of estrogen on acute lung inflammation in mice. American journal of physiology Cell physiology 2005; 288: C881-890.

14. Squadrito F, Altavilla D, Squadrito G, Campo GM, Arlotta M, Arcoraci V, Minutoli L, Serrano M, Saitta A, Caputi AP. 17Beta-oestradiol reduces cardiac leukocyte accumulation in myocardial ischaemia reperfusion injury in rat. European journal of pharmacology 1997; 335: 185-192.

15. Draijer C, Hylkema MN, Boorsma CE, Klok PA, Robbe P, Timens W, Postma DS, Greene CM, Melgert BN. Sexual maturation protects against development of lung 
inflammation through estrogen. American journal of physiology Lung cellular and molecular physiology 2016; 310: L166-174.

16. Monteiro R, Teixeira D, Calhau C. Estrogen signaling in metabolic inflammation. Mediators of inflammation 2014; 2014: 615917.

17. van Rooyen Y, Schutte AE, Huisman HW, Eloff FC, Du Plessis JL, Kruger A, van Rooyen JM. Inflammation as Possible Mediator for the Relationship Between Lung and Arterial Function. Lung 2016; 194: 107-115.

18. Hart JE, Morse L, Tun CG, Brown R, Garshick E. Cross-sectional associations of pulmonary function with systemic inflammation and oxidative stress in individuals with chronic spinal cord injury. The journal of spinal cord medicine 2016; 39: 344352.

19. Aristotle. Historia Animalium. 322 b.C.

20. Highlights WPPTR. United Nations; 2006.

21. WHO. World Health Statistics. 2014.

22. Thannickal VJ, Murthy M, Balch WE, Chandel NS, Meiners S, Eickelberg O, Selman M, Pardo A, White ES, Levy BD, Busse PJ, Tuder RM, Antony VB, Sznajder JI, Budinger GR. Blue journal conference. Aging and susceptibility to lung disease. American journal of respiratory and critical care medicine 2015; 191: 261-269.

23. Macsali F, Svanes C, Bjorge L, Omenaas ER, Real FG. Respiratory health in women: from menarche to menopause. Expert Rev Respir Med 2012; 6: 187-202.

24. Real FG, Svanes C, Macsali F, Omenaas ER. Hormonal factors and respiratory health in women--a review. Clin Respir J 2008; 2 Suppl 1: 111-119.

25. Real FG, Svanes C, Omenaas ER, Anto JM, Plana E, Janson C, Jarvis D, Zemp E, Wjst M, Leynaert B, Sunyer J. Menstrual irregularity and asthma and lung function. The Journal of allergy and clinical immunology 2007; 120: 557-564.

26. Becklake MR, Kauffmann F. Gender differences in airway behaviour over the human life span. Thorax 1999; 54: 1119-1138.

27. Real FG, Svanes C, Omenaas ER, Anto JM, Plana E, Jarvis D, Janson C, Neukirch F, Zemp E, Dratva J, Wjst M, Svanes K, Leynaert B, Sunyer J. Lung function, respiratory symptoms, and the menopausal transition. The Journal of allergy and clinical immunology 2008; 121: 72-80 e73.

28. Triebner K, Johannessen A, Puggini L, Benediktsdottir B, Bertelsen RJ, Bifulco E, Dharmage SC, Dratva J, Franklin KA, Gislason T, Holm M, Jarvis D, Leynaert B, Lindberg E, Malinovschi A, Macsali F, Norback D, Omenaas ER, Rodriguez FJ, Saure E, Schlunssen V, Sigsgaard T, Skorge TD, Wieslander G, Zemp E, Svanes C, Hustad S, Gomez Real F. Menopause as a predictor of new-onset asthma: A longitudinal Northern European population study. The Journal of allergy and clinical immunology 2015.

29. Macsali F, Real FG, Plana E, Sunyer J, Anto J, Dratva J, Janson C, Jarvis D, Omenaas ER, Zemp E, Wjst M, Leynaert B, Svanes C. Early age at menarche, lung function, and adult asthma. American journal of respiratory and critical care medicine 2010; 183: 8-14.

30. Macsali F, Svanes C, Sothern RB, Benediktsdottir B, Bjorge L, Dratva J, Franklin KA, Holm M, Janson C, Johannessen A, Lindberg E, Omenaas ER, Schlunssen V, Zemp E, Real FG. Menstrual cycle and respiratory symptoms in a general Nordic-Baltic population. American journal of respiratory and critical care medicine 2013; 187: 366-373.

31. Mair KM, Wright AF, Duggan N, Rowlands DJ, Hussey MJ, Roberts S, Fullerton J, Nilsen M, Loughlin L, Thomas M, MacLean MR. Sex-dependent influence of 
endogenous estrogen in pulmonary hypertension. American journal of respiratory and critical care medicine 2014; 190: 456-467.

32. Farha S, Asosingh K, Laskowski D, Hammel J, Dweik RA, Wiedemann HP, Erzurum SC. Effects of the menstrual cycle on lung function variables in women with asthma. American journal of respiratory and critical care medicine 2009; 180: 304-310.

33. Zemp E, Schikowski T, Dratva J, Schindler C, Probst-Hensch N. Asthma and the menopause: A systematic review and meta-analysis. Maturitas; 73: 212-217.

34. Pinkerton KE, Harbaugh M, Han MK, Jourdan Le Saux C, Van Winkle LS, Martin WJ, 2nd, Kosgei RJ, Carter EJ, Sitkin N, Smiley-Jewell SM, George M. Women and Lung Disease. Sex Differences and Global Health Disparities. American journal of respiratory and critical care medicine 2015; 192: 11-16.

35. Songur N, Aydin ZD, Ozturk O, Sahin U, Khayri U, Bircan A, Akkaya A. Respiratory symptoms, pulmonary function, and reproductive history: Isparta Menopause and Health Study. Journal of women's health (2002) 2010; 19: 1145-1154.

36. Amaral AF, Strachan DP, Gomez Real F, Burney PG, Jarvis DL. Lower lung function associates with cessation of menstruation: UK Biobank data. The European respiratory journal 2016.

37. Pata Ö. The effects of hormone replacement therapy type on pulmonary functions in postmenopausal women. Maturitas 2003; 46: 213-218.

38. Cevrioglu AS, Fidan F, Unlu M, Yilmazer M, Orman A, Fenkci IV, Serteser M. The effects of hormone therapy on pulmonary function tests in postmenopausal women. Maturitas 2004; 49: 221-227.

39. Hayatbakhsh MR, Najman JM, O'Callaghan MJ, Williams GM, Paydar A, Clavarino A. Association between smoking and respiratory function before and after menopause. Lung 2011; 189: 65-71.

40. Lukanova A, Lundin E, Zeleniuch-Jacquotte A, Muti P, Mure A, Rinaldi S, Dossus L, Micheli A, Arslan A, Lenner P, Shore RE, Krogh V, Koenig KL, Riboli E, Berrino F, Hallmans G, Stattin P, Toniolo P, Kaaks R. Body mass index, circulating levels of sex-steroid hormones, IGF-I and IGF-binding protein-3: a cross-sectional study in healthy women. European journal of endocrinology / European Federation of Endocrine Societies 2004; 150: 161-171.

41. McTiernan A, Wu L, Chen C, Chlebowski R, Mossavar-Rahmani Y, Modugno F, Perri MG, Stanczyk FZ, Van Horn L, Wang CY. Relation of BMI and physical activity to sex hormones in postmenopausal women. Obesity (Silver Spring, Md) 2006; 14: 1662-1677.

42. Gomez Real F, Svanes C, Bjornsson EH, Franklin KA, Gislason D, Gislason T, Gulsvik A, Janson C, Jogi R, Kiserud T, Norback D, Nystrom L, Toren K, Wentzel-Larsen T, Omenaas E. Hormone replacement therapy, body mass index and asthma in perimenopausal women: a cross sectional survey. Thorax 2006; 61: 34-40.

43. Triebner K, Matulonga B, Johannessen A, Suske S, Benediktsdottir B, Demoly P, Dharmage S, Franklin K, Garcia-Aymerich J, Gullón Blanco JA, Heinrich J, Holm M, Jarvis D, Jögi R, Lindberg E, Moratalla Rovira JM, Muniozguren Agirre N, Pin I, Probst-Hensch N, Puggini L, Raherison C, Sánchez-Ramos JL, Schlünssen V, Sunyer J, Svanes C, Hustad S, Leynaert B, Real FG. Menopause is associated with accelerated lung function decline. European Respiratory Society Congress 2016. London; 2016.

44. Linzer DA, Lewis JB. poLCA: An R Package for Polytomous Variable Latent Class Analysis. 2011 2011; 42: 29.

45. Harlow SD, Gass M, Hall JE, Lobo R, Maki P, Rebar RW, Sherman S, Sluss PM, de Villiers TJ. Executive summary of the Stages of Reproductive Aging Workshop + 10: 
addressing the unfinished agenda of staging reproductive aging. The Journal of clinical endocrinology and metabolism 2012; 97: 1159-1168.

46. Chinn S, Jarvis D, Melotti R, Luczynska C, Ackermann-Liebrich U, Anto JM, Cerveri I, de Marco R, Gislason T, Heinrich J, Janson C, Kunzli N, Leynaert B, Neukirch F, Schouten J, Sunyer J, Svanes C, Vermeire P, Wjst M, Burney P. Smoking cessation, lung function, and weight gain: a follow-up study. Lancet 2005; 365: 1629-1635; discussion 1600-1621.

47. Miller MR, Hankinson J, Brusasco V, Burgos F, Casaburi R, Coates A, Crapo R, Enright P, van der Grinten CP, Gustafsson P, Jensen R, Johnson DC, MacIntyre N, McKay R, Navajas D, Pedersen OF, Pellegrino R, Viegi G, Wanger J. Standardisation of spirometry. The European respiratory journal 2005; 26: 319-338.

48. Pinheiro J, Bates D, Saikat D. nlme: Linear and Nonlinear Mixed Effects Models. 2016, R package version 3.1-128 ed; 2016.

49. Huang X, Harlow SD, Elliott MR. Distinguishing 6 population subgroups by timing and characteristics of the menopausal transition. Am J Epidemiol 2012; 175: 74-83.

50. Tepper PG, Randolph JF, Jr., McConnell DS, Crawford SL, El Khoudary SR, Joffe H, Gold EB, Zheng H, Bromberger JT, Sutton-Tyrrell K. Trajectory clustering of estradiol and follicle-stimulating hormone during the menopausal transition among women in the Study of Women's Health across the Nation (SWAN). The Journal of clinical endocrinology and metabolism 2012; 97: 2872-2880.

51. Randolph JF, Jr., Zheng H, Avis NE, Greendale GA, Harlow SD. Masturbation frequency and sexual function domains are associated with serum reproductive hormone levels across the menopausal transition. The Journal of clinical endocrinology and metabolism 2015; 100: 258-266.

52. Chotirmall SH, Greene CM, Oglesby IK, Thomas W, O'Neill SJ, Harvey BJ, McElvaney NG. 17Beta-estradiol inhibits IL-8 in cystic fibrosis by up-regulating secretory leucoprotease inhibitor. American journal of respiratory and critical care medicine 2010; 182: 62-72.

53. Mittman C, Edelman NH, Norris AH, Shock NW. Relationship between chest wall and pulmonary compliance and age. Journal of Applied Physiology 1965; 20: 1211-1216.

54. Raisz LG. Pathogenesis of osteoporosis: concepts, conflicts, and prospects. The Journal of clinical investigation 2005; 115: 3318-3325. 


\section{Page 25 of 36}

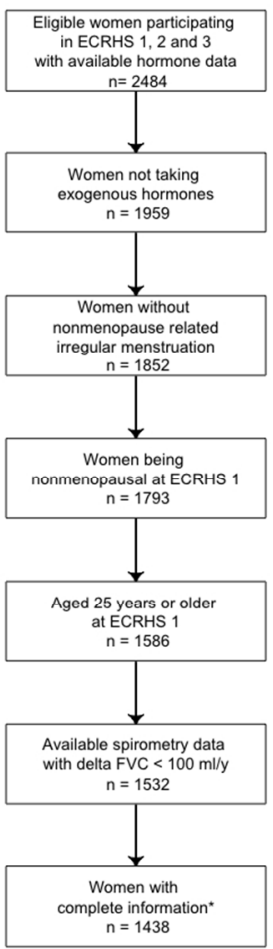

Figure 1. Study population with inclusion criteria (*height and packyears) Figure 1

$407 \times 313 \mathrm{~mm}(72 \times 72 \mathrm{DPI})$ 


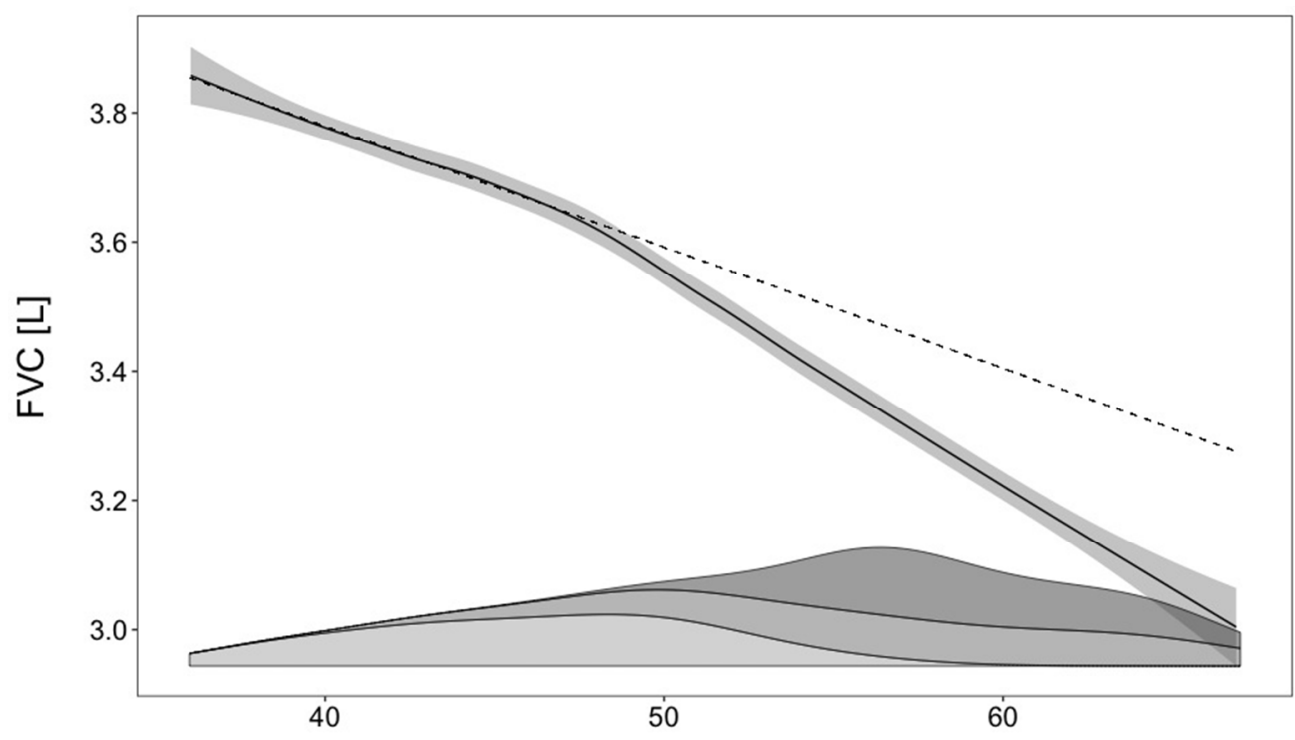

Age [yr]

Figure 2. Best linear unbiased predictions for FVC of the study population $(n=1438)$ according to the specified linear mixed effects model, including $95 \% \mathrm{CI}$ and population distribution by menopausal class (The dotted line, as visual aid continues the initial slope).

Figure 2

$333 \times 205 \mathrm{~mm}(72 \times 72$ DPI $)$ 


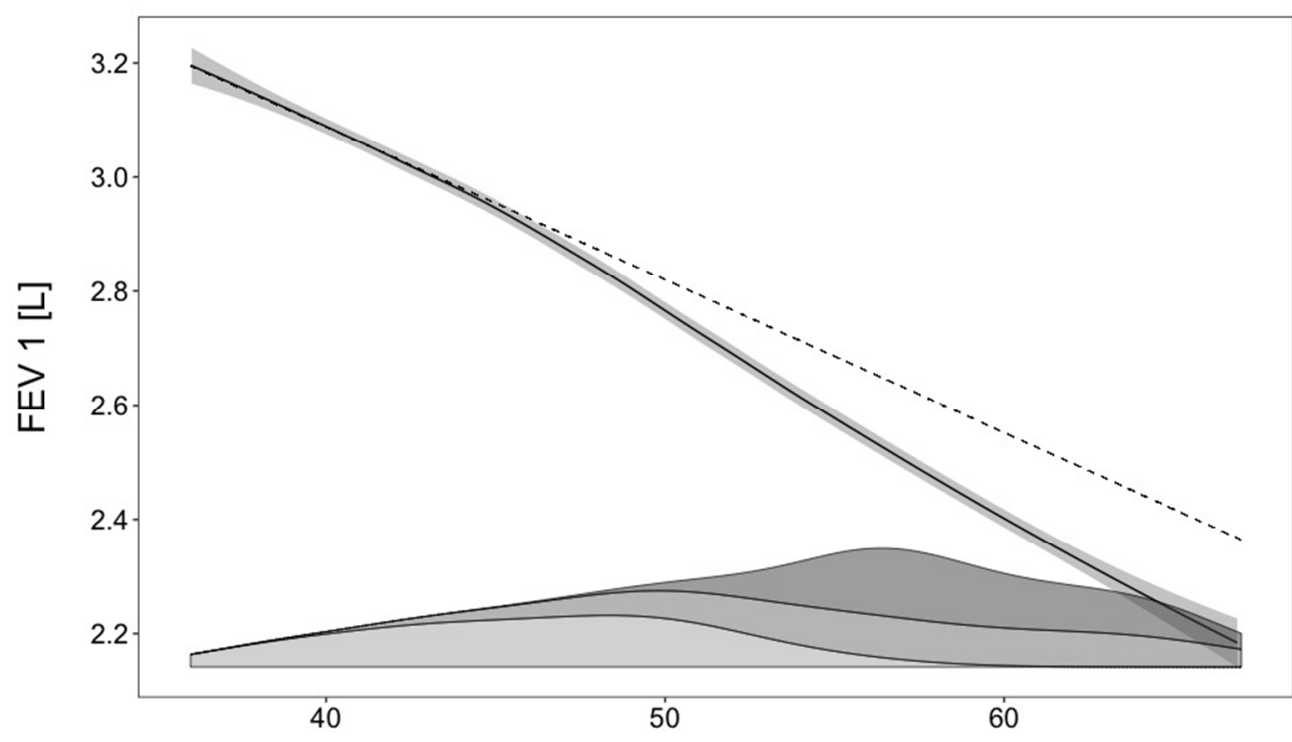

Age [yr]

Figure 3. Best linear unbiased predictions for FEV1 of the study population $(n=1438)$ according to the specified linear mixed effects model, including $95 \% \mathrm{CI}$ and population distribution by menopausal class (The dotted line, as visual aid continues the initial slope).

Figure 3

$333 \times 205 \mathrm{~mm}(72 \times 72$ DPI $)$ 


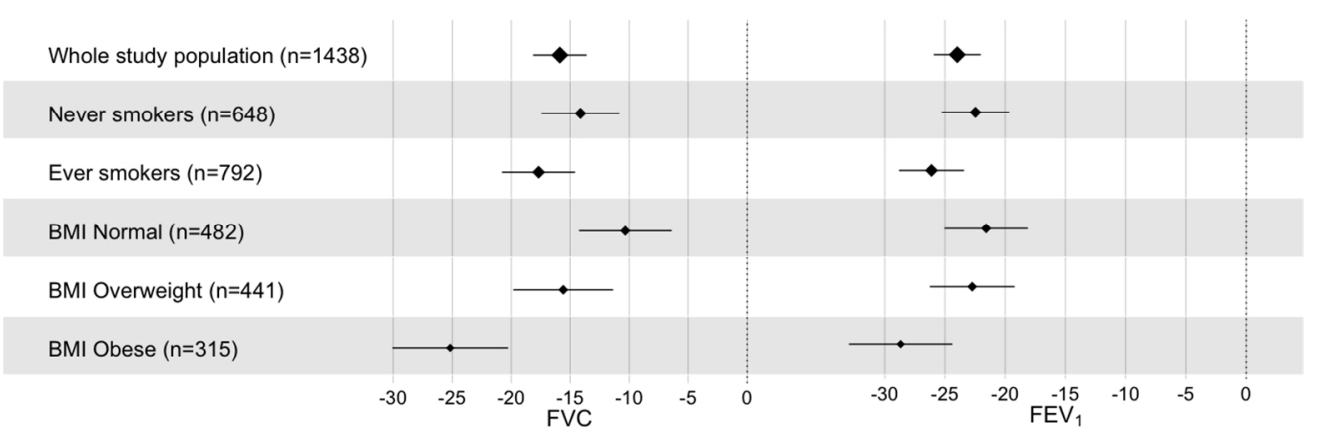

Figure 4. Age related lung function decline by smoking and BMI for the study population, $\mathrm{ml} / \mathrm{yr}$ Figure 4

$479 \times 164 \mathrm{~mm}(72 \times 72$ DPI $)$ 


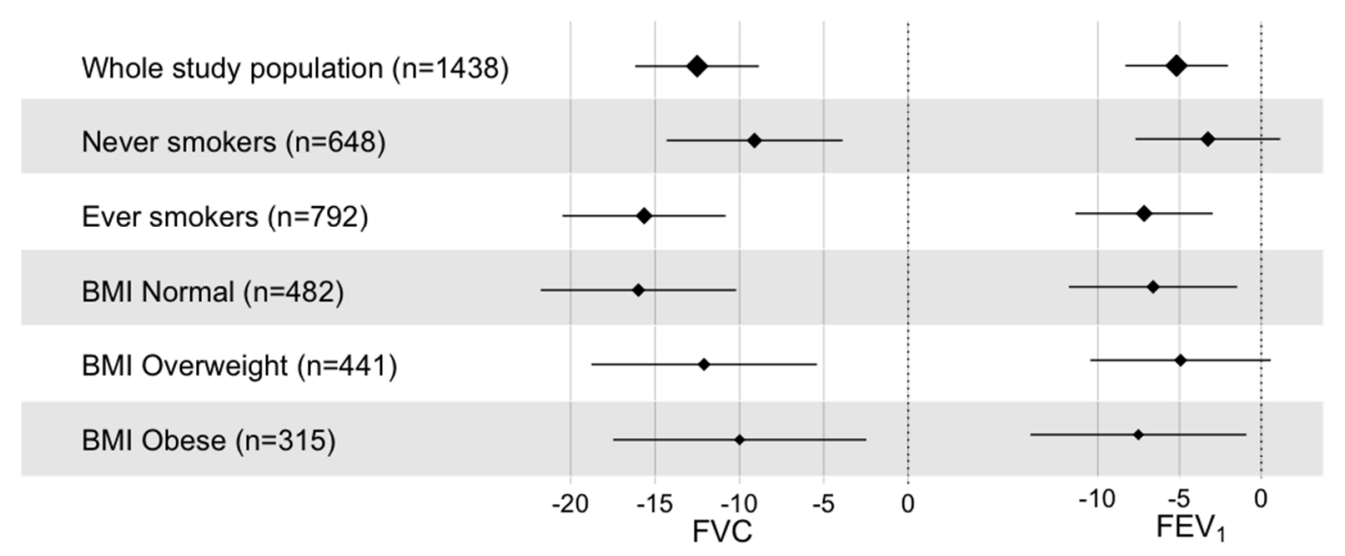

Figure 5. Menopause related lung function decline by smoking and BMI for the menopausal class, $\mathrm{ml} / \mathrm{yr}$ Figure 5 $358 \times 158 \mathrm{~mm}(72 \times 72$ DPI $)$ 


\section{ONLINE DATA SUPPLEMENT}

\section{Hormone measurements}

At ECRHS 2 the levels of FSH and LH in the serum samples were determined by chemiluminescence in an Elecsys 2010 analyzer from Roche Diagnostics (Germany) at the Hôpital Xavier Bichat in Paris, France. At ECRHS 3 we determined FSH and LH levels using enzyme-linked immunosorbent assays provided by Demeditec Diagnostics, (Germany). All pipetting steps were executed fully automated on a liquid-handling robot from Hamilton Robotics using the protocol 4Elisa at the Core Facility for Metabolomics of the University of Bergen, Norway (www.uib.no/metabolomics). For FSH, the between day coefficient of variation was $7.0 \%$ and accuracy was $106 \%$, for LH respectively $8.6 \%$ and $85 \%$.

\section{Menopausal status}

Methods: At ECRHS 2 the menstrual status was obtained from the answers to the following questions: "Are your periods regular?" (Alternatives: "Yes", "No, they have never been regular", "No they have been irregular for a few months") and "Why did your periods stop?" (Alternatives: "Naturally", "Because of surgery" and "Other"; and at ECRHS 3: "Do you have regular periods?" (Alternatives: "Yes", "No, they have never been regular", "No they have been irregular for a few months" and "No, my periods have stopped").

Results: At ECRHS 2, 52\% $(n=586)$ of the participants were categorized as nonmenopausal, $28 \%(n=311)$ as transitional and $20 \%(n=223)$ as menopausal. At ECRHS 3, 26\% $(n=367)$ of the participants were categorized as nonmenopausal, 29\% $(n=409)$ as transitional and $46 \%$ $(n=651)$ as menopausal. A reversal of menopausal status was indicated in the latent class analysis in a few cases (4\%). Excluding these women from the analysis did not alter the 
results. We kept the observations in the primary analysis with the corresponding class originally attributed by the latent class analysis.

\section{Pulmonary function data}

Pulmonary function data, including hormone measurements and a complete set of covariates was available at baseline for 1369 women (95\%), at ECRHS 2 for 866 women (60\%) and ECRHS 3 for 1060 women (74\%). Of the included women 71\% provided measurements at all three waves, $28 \%$ at two waves and $2 \%$ at one wave.

Table E1. Spirometers used by center and wave

\begin{tabular}{l|ccc}
\hline Centre & ECRHS 1 & ECRHS 2 & ECRHS 3 \\
\hline Aarhus (DK) & Vitalograph spiro & - & NDD Easyone \\
Hamburg (DE) & Jaeger pneum & Jaeger pneum & NDD Easyone \\
Erfurt (DE) & Jaeger pneum & Jaeger pneum & NDD Easyone \\
Galdakao (ES) & Biomedin spiro & Biomedin spiro & NDD Easyone \\
Albacete (ES) & Biomedin spiro & Biomedin spiro & NDD Easyone \\
Huelva (ES) & Biomedin spiro & Biomedin spiro & NDD Easyone \\
& & & \\
Bordeaux (FR) & Vitalograph spir & Vitalograph spir & NDD Easyone \\
Grenoble (FR) & Biomedin spiro & Biomedin spiro & NDD Easyone \\
Montpellier (FR) & Biomedin spiro & Biomedin spiro & NDD Easyone \\
Paris (FR) & Biomedin spiro & Biomedin spiro & NDD Easyone \\
& & & \\
Reykjavik (IS) & SensorMedics spiro & SensorMedics spiro & NDD Easyone \\
Bergen (NO) & SensorMedics spiro & SensorMedics spiro & NDD Easyone \\
& & & \\
Gothenburg (SE) & SensorMedics spiro & SensorMedics spiro & NDD Easyone \\
Umea (SE) & SensorMedics spiro & SensorMedics spiro & NDD Easyone \\
Uppsala (SE) & SensorMedics spiro & SensorMedics spiro & NDD Easyone \\
& & & \\
Tartu (EE) & Jaeger pneum & Jaeger pneum & NDD Easyone \\
\hline
\end{tabular}


Table E2. Class conditional probabilities and standard errors for the latent class analysis

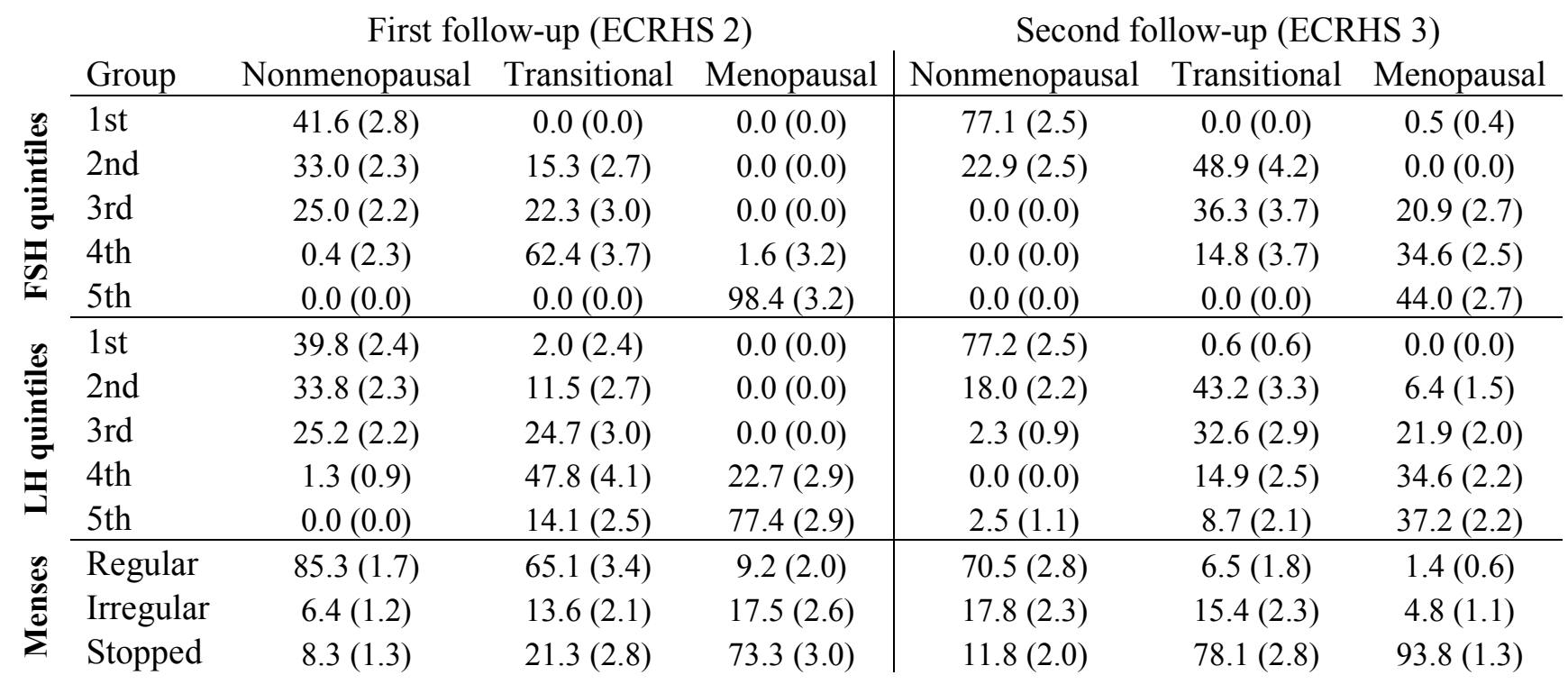

Table E3. Determinants of decline of forced vital capacity

\begin{tabular}{|c|c|c|}
\hline & Mean $(95 \% \mathrm{CI})^{4}$ & p-Value \\
\hline $\operatorname{Age}^{1}[\mathrm{ml} / \mathrm{yr}]$ & $-15.9(-18.2$ to -13.7$)$ & $<0.001$ \\
\hline Height at baseline $[\mathrm{ml} / \mathrm{cm}]$ & $52.3(48.6$ to 55.9$)$ & $<0.001$ \\
\hline Weight $[\mathrm{ml} / \mathrm{kg}]$ & $-6.5(-7.8$ to -5.3$)$ & $<0.001$ \\
\hline Packyears [ml/packyear] & $-1.0(-1.9$ to -0.1$)$ & 0.04 \\
\hline Current smoking ${ }^{2}[\mathrm{ml}]$ & $-9.4(-38.1$ to 19.3$)$ & 0.52 \\
\hline Education $^{3}[\mathrm{ml} / \mathrm{yr}]$ & $1.1(-2.9$ to 5.0$)$ & 0.60 \\
\hline \multicolumn{3}{|l|}{${ }^{1}$ Centered at median } \\
\hline \multicolumn{3}{|c|}{${ }^{2}$ Current smoking compared to former and never smokers } \\
\hline \multicolumn{3}{|l|}{${ }^{3}$ Age at completed full-time education } \\
\hline${ }^{4}$ Linear mixed effect model, intercept -4 & 5.2 to & \\
\hline
\end{tabular}

Table E4. Determinants of decline of forced expiratory volume in one second

\begin{tabular}{lcc} 
& Mean $(\mathbf{9 5 \%} \mathbf{C I})^{\mathbf{4}}$ & $\boldsymbol{p}$-Value \\
\hline Age $^{\mathbf{1}}[\mathbf{m l} / \mathbf{y r}]$ & $-24.2(-26.2$ to -22.3$)$ & $<0.001$ \\
Height at baseline [ml/cm] & $37.2(34.1$ to 40.3$)$ & $<0.001$ \\
Weight [ml/kg] & $-4.3(-5.4$ to -3.2$)$ & $<0.001$ \\
\hline Packyears [ml/packyear] & $-2.2(-3.0$ to -1.4$)$ & 0.04 \\
Current smoking ${ }^{2}$ [ml] & $-29.3(-54.0$ to -4.7$)$ & 0.02 \\
\hline Education ${ }^{3}$ [ml/yr] & $1.2(-2.2$ to 4.5$)$ & 0.50 \\
\hline${ }^{1}$ Centered at median & \\
${ }^{2}$ Current smoking compared to former and never smokers \\
${ }^{3}$ Age at completed full-time education \\
${ }^{4}$ Linear mixed effect model, intercept -3.0 L (-3.5 to -2.5)
\end{tabular}


Financial support for ECRHS I: The following grants helped to fund the local studies.

Estonia: Estonian Science Foundation, grant no 1088, France: Ministère de la Santé, Glaxo France, Insitut Pneumologique d'Aquitaine, Contrat de Plan Etat-Région LanguedocRousillon, CNMATS, CNMRT (90MR/10, 91AF/6), Ministre delegué de la santé, RNSP, France; GSF, Germany: Bundesminister für Forschung und Technologie, Norway: Norwegian Research Council project no. 101422/310; Spain: Fondo de Investigación Sanitaria ( \#91/0016-060-05/E, 92/0319 and \#93/0393), Hospital General de Albacete, Hospital General Juan Ramón Jiménez, Dirección Regional de Salud Pública (Consejería de Sanidad del Principado de Asturias), CIRIT (1997 SGR 00079) and Servicio Andaluz de Salud; Sweden: The Swedish Medical Research Council, the Swedish Heart Lung Foundation, the Swedish Association against Asthma and Allergy; Switzerland: Swiss national Science Foundation grant 4026-28099;

Financial Support for ECRHS II: Estonia: Tartu Estonian Science Foundation grant no 4350, France: (All) Programme Hospitalier de Recherche Clinique-Direction de la Recherche Clinique (DRC) de Grenoble 2000 number 2610, Ministry of Health, Ministère de l'Emploi et de la Solidarité, Direction Génerale de la Santé, Centre Hospitalier Universitaire (CHU) de Grenoble, Bordeaux: Institut Pneumologique d'Aquitaine; Grenoble: Comite des Maladies Respiratoires de 1'Isere; Montpellier: Aventis ( France), Direction Regionale des Affaires Sanitaires et Sociales Languedoc-Roussillon; Paris: Union Chimique Belge- Pharma (France),Aventis (France), Glaxo France,; Germany: Erfurt GSF-National Research Centre for Environment and Health, Deutsche Forschungsgemeinschaft (grant code, FR1526/1-1) Hamburg: GSF-National Research Centre for Environment and Health, Deutsche Forschungsgemeinschaft (grant code, MA 711/4-1) Iceland: Reykjavik, Icelandic Research Council, Icelandic University Hospital Fund; Norway: Bergen: Norwegian Research Council, Norwegian Asthma and Allergy Association, Glaxo Wellcome AS, Norway Research Fund; 
Spain: Fondo de Investigación Santaria (grant codes, 97/0035-01,99/0034-01 and 99/0034 02), Hospital Universitario de Albacete, Consejeria de Sanidad; Barcelona: Sociedad Española de Neumología y Cirugía Torácica, Public Health Service (grant code, R01 HL62633-01), Fondo de Investigaciones Santarias (grant codes, 97/0035-01, 99/0034-01, and 99/0034-02), Consell Interdepartamental de Recerca i Innovacilo Tecnol \ogica (grant code, 1999SGR 00241) Instituto de Salud Carlos III; Red de Centros de Epidemiología y SaludPública, C03/09, Red de Bases moleculares y fisiológicas de las Enfermedades Respiratorias,C03/011 and Red de Grupos Infancia y Medio Ambiente G03/176; Huelva: Fondo de Investigaciones Santarias (grant codes, 97/0035-01, 99/0034-01, and 99/0034-02); Galdakao: Basque Health Department Oviedo: Fondo de Investigaciones Sanitaria (97/003502, 97/0035, 99/0034-01, 99/0034-02, 99/0034-04, 99/0034-06, 99/350, 99/0034--07), European Commission (EU-PEAL PL01237), Generalitat de Catalunya (CIRIT 1999 SGR 00214), Hospital Universitario de Albacete, Sociedad Española de Neumología y Cirugía Torácica (SEPAR R01 HL62633-01) Red de Centros de Epidemiología y Salud Pública (C03/09), Red de Bases moleculares y fisiológicas de las Enfermedades Respiratorias (C03/011) and Red de Grupos Infancia y Medio Ambiente (G03/176);97/0035-01, 99/003401, and99/0034-02); Sweden: Göteborg, Umea, Uppsala: Swedish Heart Lung Foundation, Swedish Foundation for Health Care Sciences and Allergy Research, Swedish Asthma and Allergy Foundation, Swedish Cancer and Allergy Foundation, Swedish Council for Working Life and Social Research (FAS),Switzerland: Basel Swiss National Science Foundation, Swiss Federal Office for Education and Science, Swiss National Accident Insurance Fund;

Financial Support for ECRHS III: Estonia: Tartu- SF0180060s09 from the Estonian Ministry of Education. France: (All) Ministère de la Santé. Programme Hospitalier de Recherche Clinique (PHRC) national 2010 ; Bordeaux: INSERM U897 Université Bordeaux segalen Grenoble: Comitee Scientifique AGIRadom 2011. Paris: Agence Nationale de la 
Santé, Région Ile de France, domaine d'intérêt majeur (DIM) Germany : Erfurt: German Research Foundation HE 3294/10-1 Hamburg: German Research Foundation MA 711/6-1, NO 262/7-1 Iceland: Reykjavik, The Landspitali University Hospital Research Fund, University of Iceland Research Fund, ResMed Foundation, Vegagerðin (The Icelandic Road Administration (ICERA ) Norway: Norwegian Research Council, grant no 214123, Western Norway Regional Health Authorities grant no 911631, Bergen Medical Research Foundation. Spain: Fondo de Investigación Sanitaria (PS09/02457, PS09/00716 09/01511) PS09/02185 PS09/03190), Servicio Andaluz de Salud, Sociedad Española de Neumología y Cirurgía Torácica (SEPAR 1001/2010); Sweden: All centres were funded by The Swedish Heart and Lung Foundation, The Swedish Asthma and Allergy Association, The Swedish Association against Lung and Heart Disease.Fondo de Investigación Sanitaria (PS09/02457 Barcelona:Fondo de Investigación Sanitaria (FIS PS09/00716) Galdakao: Fondo de Investigación Sanitaria (FIS 09/01511) Huelva: Fondo de Investigación Sanitaria (FIS PS09/02185) and Servicio Andaluz de Salud Oviedo: Fondo de Investigación Sanitaria (FIS PS09/03190) Sweden: All centres were funded by The Swedish Heart and Lung Foundation, The Swedish Asthma and Allergy Association, The Swedish Association against Lung and Heart Disease. Swedish Research Council for health, working life and welfare (FORTE) Göteborg : Also received further funding from the Swedish Council for Working life and Social Research. Umea also received funding from Vasterbotten Country Council ALF grant. Switzerland: The Swiss National Science Foundation (grants no 33CSCO-134276/1, 33CSCO-108796, 3247BO-104283, 3247BO-104288, 3247BO-104284, 3247-065896, 3100059302, 3200-052720, 3200-042532, 4026-028099) The Federal office for forest, environment and landscape, The Federal Office of Public Health, The Federal Office of Roads and Transport, the canton's government of Aargan, Basel-Stadt, Basel-Land, Geneva, Luzern, Ticino, Valais and Zürich, the Swiss Lung League, the canton's Lung League of 
Basel Stadt/ Basel, Landschaft, Geneva, Ticino, Valais and Zurich, SUVA, Freiwillige Akademische Gesellschaft, UBS Wealth Foundation, Talecris Biotherapeutics GmbH, Abbott Diagnostics, European Commission 018996 (GABRIEL), Wellcome Trust WT 084703MA The French Agence Nationale de la Recherche (ANR) for ECRHS II hormone measures. 